\title{
Development of New Analytical Method for Estimation of Lansoprazole in Bulk and Tablet dosage forms
}

\author{
Karajgi S $\mathbf{R}^{2^{\star}}$, Mallikarjun $\mathrm{D} \mathrm{T}^{1}$, Somashekhar $\mathbf{M}^{1}$, Shivakumar $\mathrm{B}^{1}$ \\ 'Department of Pharmaceutical Chemistry, BLDEA's SSM College of Pharmacy and \\ research center Vjaypur-586101, India \\ ${ }^{2}$ Department of Quality Assurance, BLDEA's SSM College of Pharmacy and research \\ center Vjaypur-586101, India
}

\begin{abstract}
The present paper reports a simple, accurate and precise spectroscopic technique for estimation of Lansoprazole by first order derivative technique in tablet dosage form. The spectroscopic method for estimation of Lansoprazole by first order derivative technique was carried out using methyl alcohol as solvent. The absorbance maximum was $275 \mathrm{~nm}$. Beers law observed in the range of $30-150 \mu \mathrm{g} / \mathrm{ml}$ concentration. The recovery studies demonstrated the accuracy of the proposed procedure and the results were established as per ICH guidelines. The technique was used successfully for the estimation of Lansoprazole in bulk and tablet and pure dosage form.
\end{abstract}

Keywords : Lansoprazole, spectrophotometric determination, first order derivative method

\section{Introduction}

Lansoprazole is a proton-pump inhibitor (PPI's) which belongs to gastric acid inhibitory agent strongly enhances intra gastric $\mathrm{pH}$. This drug is used for treatment of short time active erosive reflux esophagus infection, wounds in the stomach and also in duodenal part of small intestine. This drug also indicated for largeterm controlling treatment in patients with reflux esophagus infection and curessmall intestine part that is duodenal ulcer and in the therapy Zollinger-Ellison syndrome ${ }^{1-5}$.

Structure

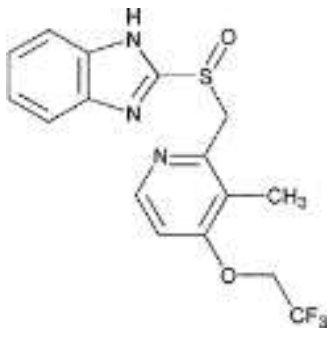

Fig 1: Chemical Structure of Lansoprazole

Karajgi S R et al /International Journal of PharmTech Research, 2019,12(4): 63-69.

DOI: http://dx.doi.org/10.20902/IJPTR.2019.120409 


\section{Review of Literature:}

As per the literature survey, only few methods are available for the determination of Lansoprazole in bulk and dosage forms so far, one UPLC method ${ }^{1}$, two HPLC methods ${ }^{2,3}$ and two UV spectrophotometric methods $^{3,4}$. There is no First derivative UV spectrophotometric method is reported and is the basis for present study.

\section{Material and Methods}

\section{a) Materials}

Standard drugLansoprazole: gift sample

Tablet Formulation:

Brand A- Lanzol 15 (Cipla)Each Uncoated tablet contains:Lansoprazole IP 15mg

Chemicals and reagents: Methyl Alcohol (AR Grade)

Instruments: Shimadzu 1800 UV (Shimadzu Japan) spectrophotometer with $1 \mathrm{~cm}$ matched quartz cells was used for estimation.

Selection of media : Main criteria of media selection and stability, i.e. drug should be soluble as well as stable for sufficient time in selected media. For present work methanol has been selected as analytical media.

\section{b) Method}

Preparation of standard stock solution : The standard stock solution was prepared by taking 50mg of standard powder Lansoprazole pure drug in $25 \mathrm{ml}$ of methanol in a $50 \mathrm{ml}$ volumetric flask,shaken vigorously and made the volume up to $50 \mathrm{ml}$ i.e $1000 \mu \mathrm{g} / \mathrm{ml}$.from that solution pipette out $5 \mathrm{ml}$ and added in a another volumetric flask and made the volume up to $50 \mathrm{ml}$ with the help of methanol i.e $100 \mu \mathrm{g} / \mathrm{ml}$.

Determination of $\lambda$ max: Taken $5 \mathrm{ml}$ of Lansoprazole from above standard stock solution and transferred into $50 \mathrm{ml}$ volume flask made the volume upto $50 \mathrm{ml} \mathrm{i.e} 10 \mu \mathrm{g} / \mathrm{ml}$. The solution was scanned in the UV range $200-400 \mathrm{~nm}$ the $\lambda$ max was found to be $275 \mathrm{~nm}$ the spectrum of Lansoprazole was recorded.

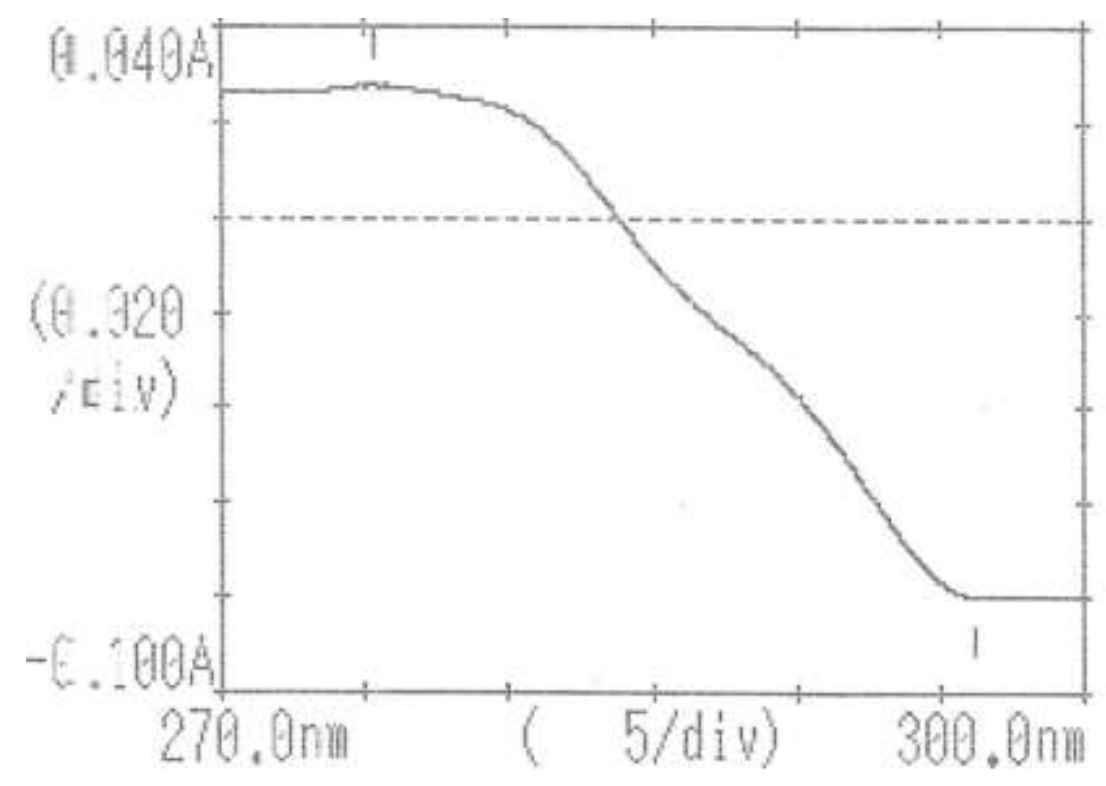

Fig 2:First order derivative spectrum of Lansoprazole 10 $\mu \mathrm{g} / \mathrm{ml}$ 


\section{Study of Beer-Lambert's Law}

From the standard stock solution of Lansoprazole, appropriate aliquots were pipette out into $50 \mathrm{ml}$ volumetric flask and dilution were made with Methanol to obtain concentrations of 30,60,90,120,150 $\mu \mathrm{g} / \mathrm{ml}$. The difference in absorbance $(\mathrm{dA} / \mathrm{d} \lambda)$ of Lansoprazole were measured in the first derivative mode with $\mathrm{N}=9$ of instrument at $275 \mathrm{~nm}$ for Lansoprazole. The caliberation curve of the drug was plotted. The concentration range over which the drugs followed linearity was chosen as an analytical concentration range i.e. $30-60 \mu \mathrm{g} / \mathrm{ml}$ for Lansoprazole.

Table 1: Standard calibration table for Lansoprazole at $275 \mathrm{~nm}$

\begin{tabular}{|l|l|l|}
\hline Sr. No. & Conc. $\boldsymbol{\mu g} / \mathbf{m l}$ & Abs. at $\mathbf{2 7 5} \mathbf{~ n m}$ \\
\hline 1 & 30 & 0.028 \\
\hline 2 & 60 & 0.073 \\
\hline 3 & 90 & 0.134 \\
\hline 4 & 120 & 0.170 \\
\hline 5 & 150 & 0.225 \\
\hline
\end{tabular}

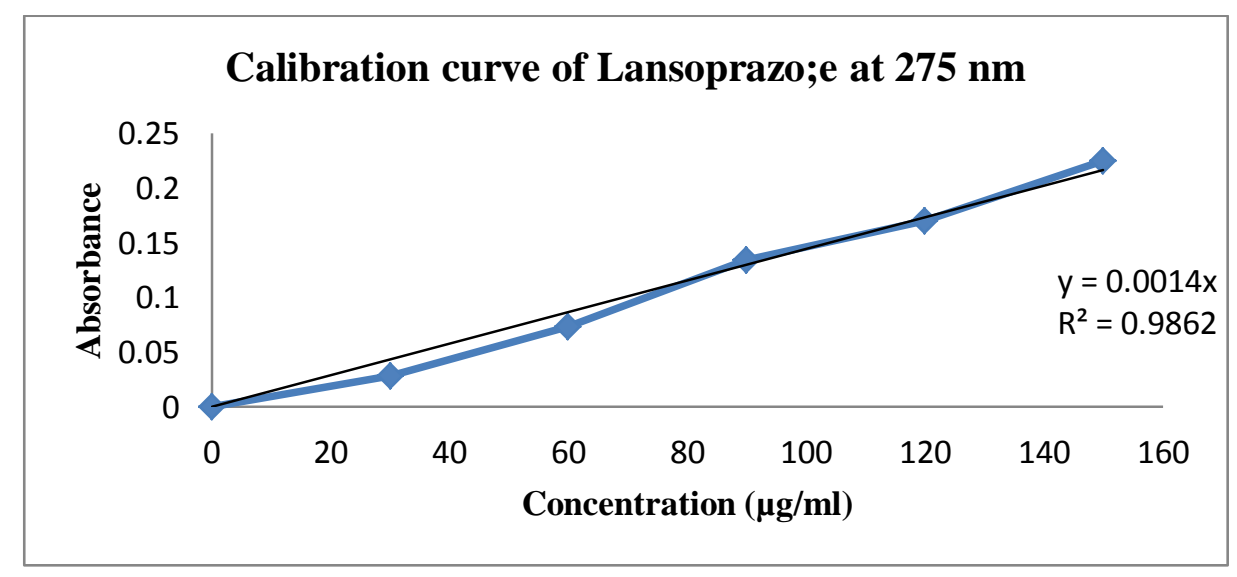

Fig 3: Calibration curve of Lansoprazole at 275 nm

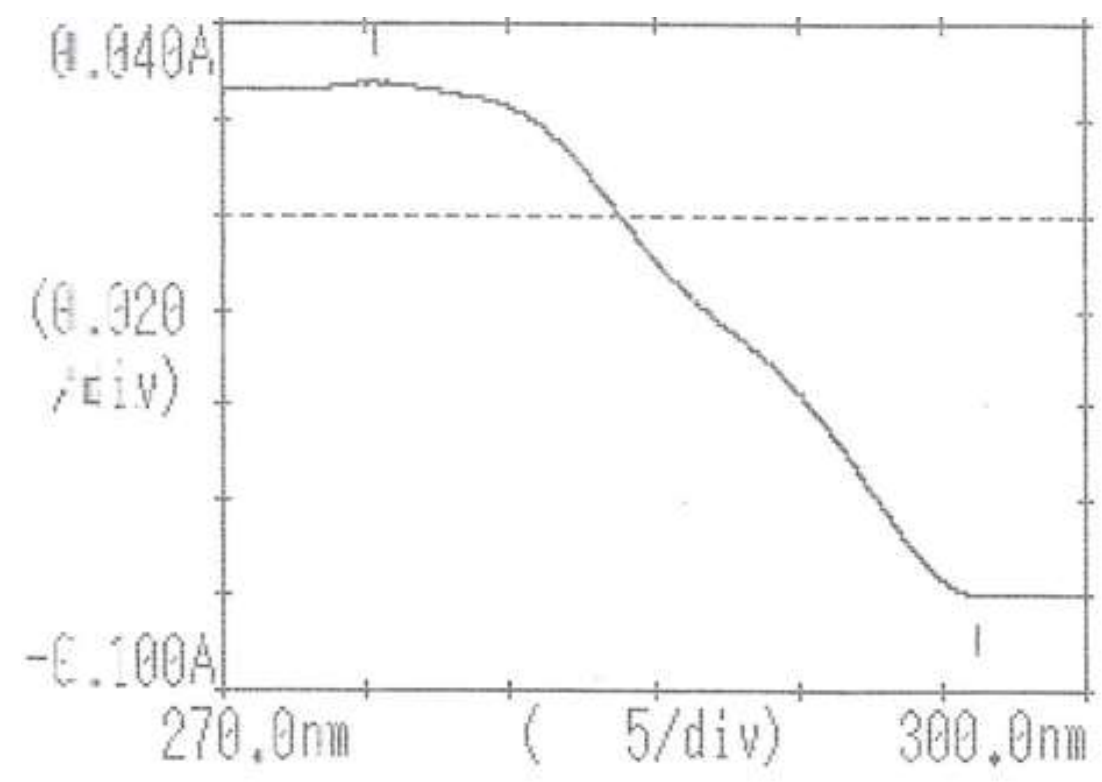

Fig 4: First order derivative spectrum ofLansoprazole30 $\mu \mathrm{g} / \mathrm{ml}$ 


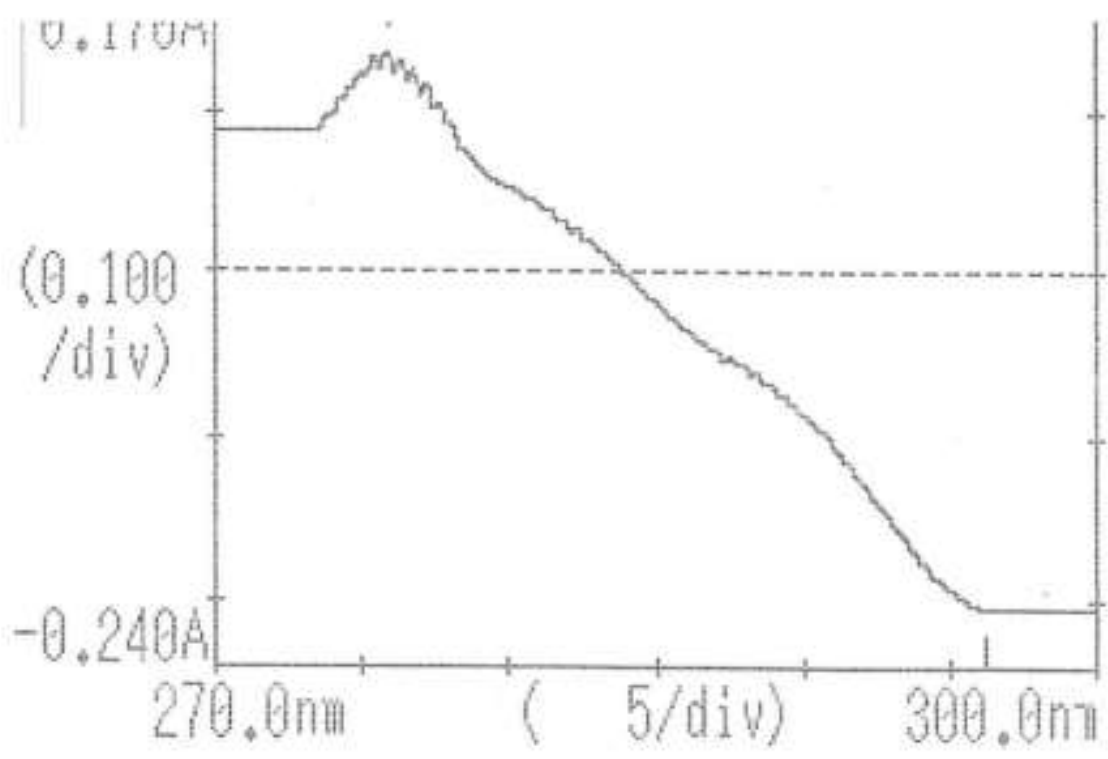

Fig 5: First order derivative spectrum of Lansoprazole $90 \mu \mathrm{g} / \mathrm{ml}$

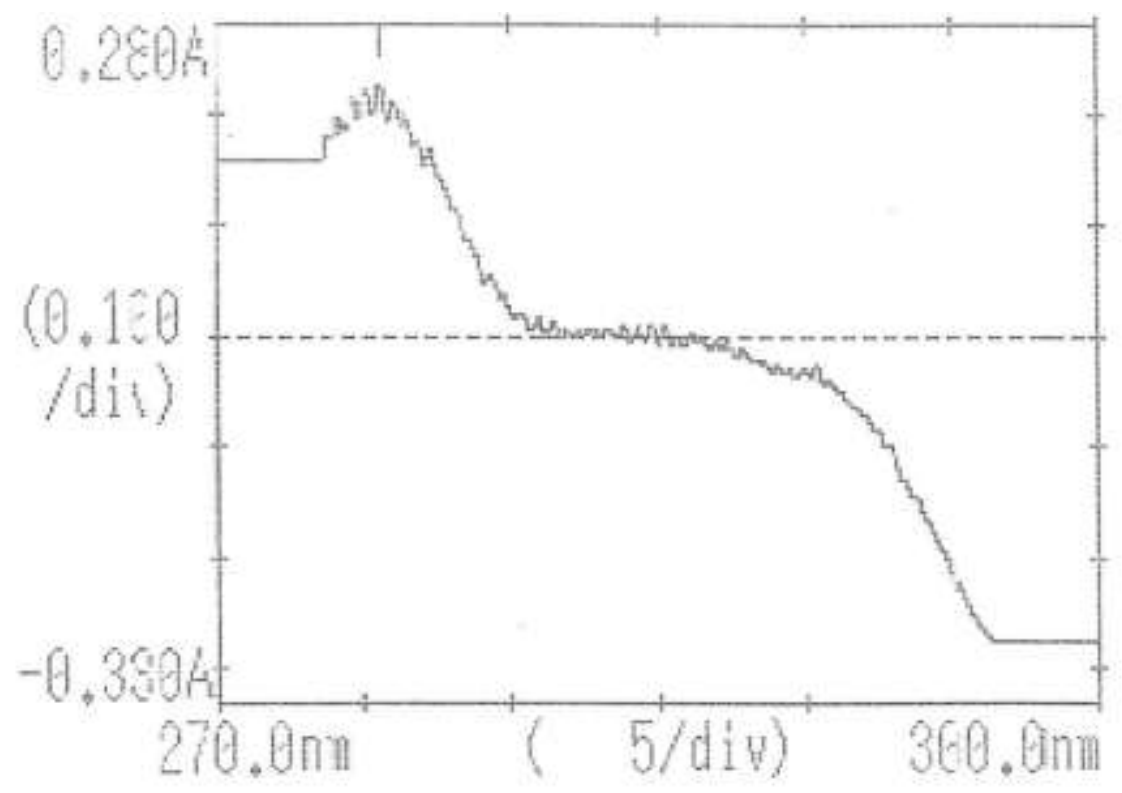

Fig 6: First order derivative spectrum of Lansoprazole150 $\mu \mathrm{g} / \mathrm{ml}$

Optical Parameters for the Calibration curve.

The optical Parameters of the calibration curves are given below

Table 2: Optical and regression Parameters of the Calibration Curve

\begin{tabular}{|l|l|}
\hline Parameter & Lansoprazole \\
\hline Linearity range & $30-150 \mu \mathrm{g} / \mathrm{ml}$ \\
\hline Slope & 0.0016 \\
\hline Intercept & -0.0213 \\
\hline Regression coefficient & 0.986 \\
\hline
\end{tabular}




\section{Validation of proposed method:}

a) Estimation of drug from dosage form : (Tablet assay study) : Twenty tablets of lanzol 15 taken and weighed their individual weight and crushed and made the powder. A quantity of powder sample equivalent to $15 \mathrm{mg}$ of Lansoprazole was taken in volumetric flask and dissolved in Methanol.Further dilution was made to obtain $100 \mu \mathrm{g} / \mathrm{ml}$. These concentration was scanned at wavelength of $275 \mathrm{~nm}$ in first order derivative mode with $\mathrm{N}=9$

The results and statistical parameters for tablet analysis are shown below.

Table 3:Assay of Lansoprazole in tablet formulation

\begin{tabular}{|c|c|c|c|c|c|c|}
\hline Drug & $\begin{array}{l}\text { Label } \\
\text { claim } \\
\text { (mg/tab) }\end{array}$ & $\begin{array}{l}\text { Amount } \\
\text { found } \\
\text { (mg/tab) }\end{array}$ & $\begin{array}{l}\text { \%o of Label } \\
\text { claim }\end{array}$ & Mean \% & SD & $\mathrm{CV}$ \\
\hline \multirow{6}{*}{$\begin{array}{l}\text { Lansopraz } \\
\text { ole } 15 \mathrm{mg} \\
\text { tablet }\end{array}$} & 15 & 15.12 & 100.80 & \multirow{6}{*}{100.35} & \multirow{6}{*}{3.962} & \multirow{6}{*}{0.0056} \\
\hline & 15 & 14.95 & 99.66 & & & \\
\hline & 15 & 14.92 & 99.46 & & & \\
\hline & 15 & 15.13 & 100.80 & & & \\
\hline & 15 & 15.09 & 100.60 & & & \\
\hline & 15 & 15.12 & 100.80 & & & \\
\hline
\end{tabular}

b) Accuracy (Recovery Test) : Accuracy of the method was studied by recovery experiments. The recovery experiments were performed by adding known amounts to tablet. The recovery was performed at three levels, 80, 100and $120 \%$ of Lansoprazole standard concentration. The recovery samples were prepared in above mentioned procedure. Three samples were prepared for every recovery level. The solutions were analyzed, and the percentage recoveries were calculated by using formula

$\%$ Recovery $=\frac{\text { Observed amount of compound in sample }}{\text { Amount of all compound present in sample }} \times 100$

Table 4: Results of accuracy parameter of Lansoprazole for Lanzol tablet 15mg.

\begin{tabular}{|c|c|c|c|c|c|c|c|}
\hline $\begin{array}{l}\text { Level of } \\
\text { \% } \\
\text { Recovery }\end{array}$ & $\begin{array}{l}\text { Amount } \\
\text { present } \\
(\mu \mathrm{g} / \mathrm{ml})\end{array}$ & $\begin{array}{l}\text { Amount } \\
\text { of } \\
\text { standard } \\
\text { added } \\
(\mu \mathrm{g} / \mathrm{ml})\end{array}$ & $\begin{array}{l}\text { Total } \\
\text { amount } \\
\text { recovered } \\
(\mu \mathrm{g} / \mathrm{ml})\end{array}$ & $\begin{array}{l}\text { \% } \\
\text { Recovery }\end{array}$ & $\begin{array}{l}\text { \% mean } \\
\text { recovery }\end{array}$ & SD & $\mathrm{CV}$ \\
\hline 80 & 15 & 12 & 27.19 & 100.70 & \multirow{3}{*}{100.90} & \multirow{9}{*}{0.7652} & \multirow{9}{*}{0.0076} \\
\hline 80 & 15 & 12 & 27.52 & 101.92 & & & \\
\hline 80 & 15 & 12 & 27.05 & 100.10 & & & \\
\hline 100 & 15 & 15 & 30.08 & 100.20 & \multirow{3}{*}{100.65} & & \\
\hline 100 & 15 & 15 & 30.58 & 101.93 & & & \\
\hline 100 & 15 & 15 & 29.95 & 99.83 & & & \\
\hline 120 & 15 & 18 & 32.92 & 99.75 & \multirow{3}{*}{100.25} & & \\
\hline 120 & 15 & 18 & 33.19 & 100.57 & & & \\
\hline 120 & 15 & 18 & 33.15 & 100.45 & & & \\
\hline
\end{tabular}

Precision study : The dilution was made to get conc. Of $50 \mu \mathrm{g} / \mathrm{ml}$ of Lansoprazole and scanned at wavelength $275 \mathrm{~nm}$ in first order derivative mode by four different analyst using same laboratory and same instrument .The precision values of Lansoprazole given below. 
Table 5: Determination of precision of Lansoprazole

\begin{tabular}{|l|l|l|l|l|}
\hline \multirow{2}{*}{$\begin{array}{l}\text { Sample } \\
\text { Number }\end{array}$} & \multicolumn{4}{|l|}{ Assay of Lansoprazole as \%of Labelled amount } \\
\cline { 2 - 5 } & Analyst-I & Analyst-II & Analyst-III & Analyst-IV \\
\hline 1 & 100.17 & 100.15 & 100.05 & 100.09 \\
\hline 2 & 100.10 & 99.89 & 100.15 & 100.17 \\
\hline 3 & 100.15 & 100.04 & 99.92 & 99.94 \\
\hline 4 & 100.05 & 99.90 & 99.95 & 100.15 \\
\hline 5 & 99.85 & 100.12 & 100.12 & 100.10 \\
\hline 6 & 100.15 & 100.05 & 100.15 & 100.05 \\
\hline Mean $\%$ & 100.07 & 100.02 & 100.05 & 100.08 \\
\hline SD & 0.1096 & 0.0994 & 0.0858 & 0.0752 \\
\hline CV & 0.0010 & 0.0009 & 0.0009 & 0.0006 \\
\hline
\end{tabular}

\section{Results:}

The standard solution of Lansoprazole in methanol $(10 \mu \mathrm{g} / \mathrm{ml})$ subjected to a scan at the wavelength of $200 \mathrm{~nm}$ to $400 \mathrm{~nm}$ at first order derivative order mode and the first order derivative spectra was taken at $\mathrm{N}=9$ using shimadzu 1800 spectronic UV visible spectrophotometer. $\lambda \max$ of Lansoprazole was found to be at $275 \mathrm{~nm}$. The calibration curve of Lansoprazole was found to be linear in the range of $30-150 \mu \mathrm{g} / \mathrm{ml}$. at $275 \mathrm{~nm}$ as in figure 3 to 6 . Therefore it was clear that Lansoprazole can be determined with no interference of any unrelated substance in single dosage form. For the determining the achievability of the developed technique for the estimation of commercially available brands of medicinal formulations, the technique was initially attempted on bulk drugs in their synthetic sample and concentration were estimated. Then the technique was subjected to the assay of tablets in marketed dosage brands and adequate results were attained within the acceptable limits as per the content of the label claim for Lansoprazolein Table 3.

The recovery experiments were conducted by adding known amounts to tablet. The recovery was performed at three levels 80,100 and $120 \%$ of Lansoprazole standard concentration. Three samples were prepared for each recovery level. The solutions were then analyzed and the percentage recoveries were found to be satisfactory within the acceptable limitsas per the content of theclaim for marketed tabletasTable 5.The method was developed successfully for Lansoprazole in its single dosage form by first order derivative method.

\section{Discussion}

Based on the above result, aim of the present study was an effort for the development of analytical techniques for the estimation of some selected combinations or single drugs present in their synthetic bulk mixtures and multi-component formulations for cost effective routine analysis like dissolution studies, determination of drugs in biological fluids, simultaneous release studies, and simultaneous kinetic studies etc. The other advantage is its applicability for the routine analysis for various routine investigations like dissolutions studies, rate determinations studies, release studies, pharmaco-kinetic studies, bioavailability studies and other common day to day evaluations. Another application of this technique is its cost-effectiveness and it is the primary advantage over high performance liquid chromatographic methods of analytical investigation. The method employs methyl alcohol as the only solvent and no other reagent is required.

\section{Conclusion}

The proposed method for selected drug is found to be accurate and precise. However, this method is more reproducible. The results and the statistical parameters demonstrate that the proposed UV spectrophotometric method is simple, rapid, specific, accurate and precise. The most prominent attribute of spectrophotometric methods are their simplicity and rapidity. Result of validation parameters confirmed that these analytical procedures are suitable for its intended purpose and meet up the criteria defined in ICH Q2/B. 


\section{References}

1. Singh S., Choudhary N.R., Inamullah, Sharma S., YadavA.K.,Gautam H., Chaturvedi S. and Agrawal V.K., Validated RP-UPLC Method Development for Estimation of Lansoprazole in Tablet Dosage Form, Int. J. of Pharm. Sci, and Drug Res., 2013, 5(3), 105-107.

2. Muthu Kumar S., Selvakumar D., T. Rajkumar E., Udhaya Kumar A.,Subageetha and Dinesh D., Development and validation of RP-HPLC method for the estimation of Lansoprazole in tablet dosage form, J. Chem. Pharm. Res., 2010, 2(6), 291-295.

3. Idrees F., Momani A. and Majdoleen H.R., Validation of HPLC and FIA Spectrophotometric Methods for the Determination of Lansoprazole in Pharmaceutical Dosage Forms and Human Plasma, American J. Anal. Chem., 2010, 1, 34-39.

4. Anil kumar A., Venkataramana K., Narasimharaju C.H.and Sudhakararao G., A simple UV spectrophotometric method for determination Of Lansoprazole in bulk and pharmaceutical dosage forms, Int. J. Pharm. and Biosci., 2012, 2(4), 524-528. 